\title{
Correction to: Quality use of diagnostic imaging in trauma, and the impact on emergency medical practice-a retrospective clinical audit
}

\author{
Robert Peter Klein ${ }^{1} \cdot$ Gary Velan $^{1} \cdot$ Noel Young ${ }^{1,2} \cdot$ Amith Shetty $^{3} \cdot$ Michelle Moscova $^{1}$ \\ Published online: 19 March 2021 \\ (C) American Society of Emergency Radiology 2021
}

Correction to: Emergency Radiology (2021). https://doi.org/10.1007/s10140-021-01921-6

The original article contains an error in Fig. 3. The figure and the percentages shown on it are both correct, but the number in brackets for one pair of the bars, the SRMO pair of bars, has a typographical error. The text reference in the paper to the figure also shows the incorrect number in brackets. The corrected version of the figure is presented here.

The original article has been corrected.

\section{Declarations}

Conflict of interest None.

Publisher's note Springer Nature remains neutral with regard to jurisdictional claims in published maps and institutional affiliations.

The online version of the original article can be found at https://doi.org/ 10.1007/s10140-021-01921-6

Michelle Moscova

m.moscova@unsw.edu.au

1 Faculty of Medicine \& Health, University of New South Wales, Sydney, NSW 2052, Australia

2 Department of Radiology, Westmead Hospital, Darcy Rd, Westmead, NSW 2145, Australia

3 Department of EmergencyMedicine, Westmead Hospital, Darcy Rd, Westmead, NSW 2145, Australia 